\title{
En memoria del Dr. José René Sánchez Bascuñán
}

\author{
Mauricio González M. ${ }^{1,2}$, Juan Pablo Ortega R. ${ }^{1}$, Gustavo Walsen A. ${ }^{1,3}$, \\ Blanca Norero M. ${ }^{1,4}$ y Alex Arenas A. ${ }^{1,4}$
}

In memory of Dr. José René Sánchez Bascuñán

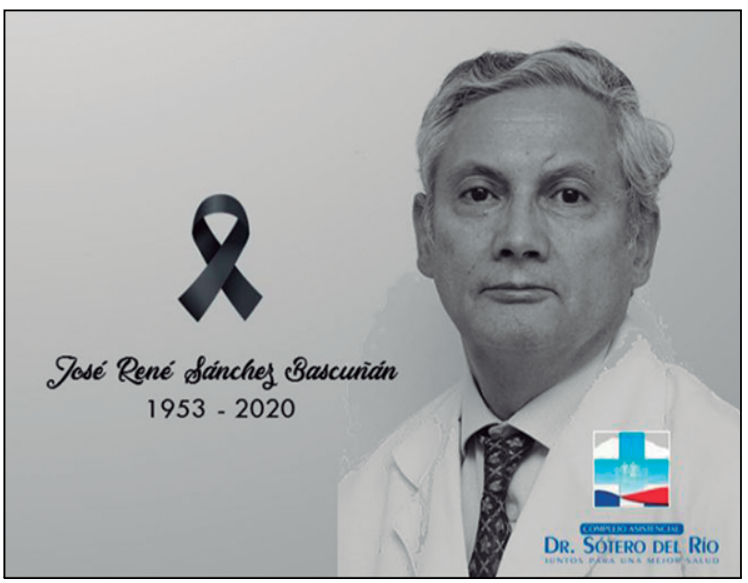

Dr. José René Sánchez ${ }^{3}$

Ante su inesperado fallecimiento, como colegas de su querido Hospital Dr. Sótero del Río, vivimos semanas de un profundo pesar. En estos difíciles momentos, en que debemos aún más que nunca estar de pie ante el gran desafío que enfrenta nuestro país, el legado de José René Sánchez surge como una gran inspiración para nuestro equipo.

Erich Fromm nos enseñó que el amor es un arte, el fruto de un aprendizaje. Por ello, si queremos aprender a amar debemos actuar como lo haríamos si quisiéramos aprender cualquier otro arte, ya sea la música, la pintura, la carpintería o el arte de la medicina ${ }^{1}$.

René Sánchez estudió en Santiago, en el colegio Verbo Divino, donde se destacó por ser el mejor alumno de su promoción. Desde temprana edad manifestó un profundo interés por estudiar medicina, sueño que cumplió en 1970, entrando a la Escuela de Medicina de la Pontificia Universidad Católica de Chile (PUC), donde fue apodado como el "Torbellino" por su incansable búsqueda de aprender.

Luego al egresar, se embarcó en la desafiante y exigente aventura de ser Médico General de Zona. Llegó al Hospital de Los Lagos (Región de los Ríos) en el año 1979, donde inmediatamente asumió como director del recinto hospitalario hasta el año 1984, desarrollando lazos indivisibles de amistad que hasta el día de hoy perduran. En honor a la huella indeleble que dejó por aquellos años, los funcionarios de dicho centro han propuesto recientemente que el hospital lleve su nombre ${ }^{2}$.

Fue en esta localidad donde conoció a quien sería su esposa, Ana María Birke, tecnóloga médica de profesión, con quien tuvo cuatro hijos, quienes fueron su desvelo permanente y culpables de sus más grandes alegrías. René vivió el amor de pareja y de padre como dijo Neruda; él sabía que en lo más profundo de su ser, estaba hecho para ellos. Sería injusto no mencionar a sus padres y hermanos, con quienes también siempre conjugó el verbo amar.

Al regresar a Santiago con su familia, empezó su formación de especialista en Medicina Interna en la PUC y, posteriormente, su gran trayectoria en la Unidad de Gastroenterología del Hospital Dr. Sótero del Río, donde forjó profundos lazos de amistad con los doctores José Brkljaca y Fernando Gutiérrez, quienes fueron sus camaradas por décadas y con quienes solía asistir a los cursos de avances y congresos de la especialidad.

Su interés por la academia y la docencia nunca se detuvieron. Fue docente de la Escuela de Medicina PUC por muchos años, siendo partícipe de la formación de cientos de médicos, son numerosas las generaciones que recuerdan sus seminarios de semiología clínica al lado de la cama del paciente.

Todo quien lo conoció destacó en él su candidez, simpleza y humildad, cualidades que lo caracterizaban, era una persona de pocas palabras, más bien reservado, silencioso y de muy bajo perfil, así lo recuerda el Dr. Felipe Finkelstein: "Lo conocí en 1986 cuando llegó al Sótero. Tranquilo, callado, de pocas palabras, buen amigo, buen hombre, buen esposo, buen padre, buen médico y muy trabajador.
Servicio de

Gastroenterología Hospital Sótero del Río. Santiago, Chile.

${ }^{2}$ Servicio de

Gastroenterología, Hospital San Borja Arriarán. Santiago, Chile.

Servicio de

Gastroenterología, Clínica Alemana de Santiago. Santiago, Chile.

${ }^{4}$ Departamento de Gastroenterología. Escuela de Medicina. Facultad de Medicina, Pontificia Universidad Católica de Chile. Santiago, Chile.

Recibido: 3 de julio de 2020 Aceptado: 4 de julio de 2020

\section{Correspondencia a:} Dr. Alex Arenas A. Departamento de Gastroenterología, Pontificia

Universidad Católica de Chile. Marcoleta \#367, Santiago, Chile. Tel: [ + +56 2] 2354 3820 afarenas@gmail. com 


\section{Gastroenterología y algo más}

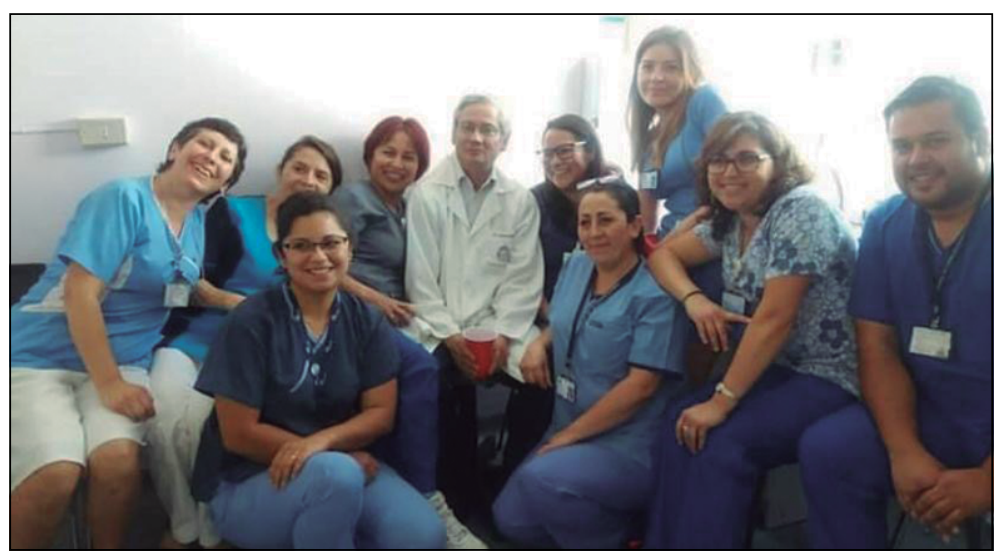

Equipo de Centro Endoscópico Hospital Sótero del Río, de izquierda a derecha: Ana Hidalgo, Eugenia Porras, María Teresa Muñoz, Margarita Seferino, Dr. José René Sánchez, Paula Velásquez, María Silva, Jocelyn Morales, Leslie Sayes, Patricio Catalán.

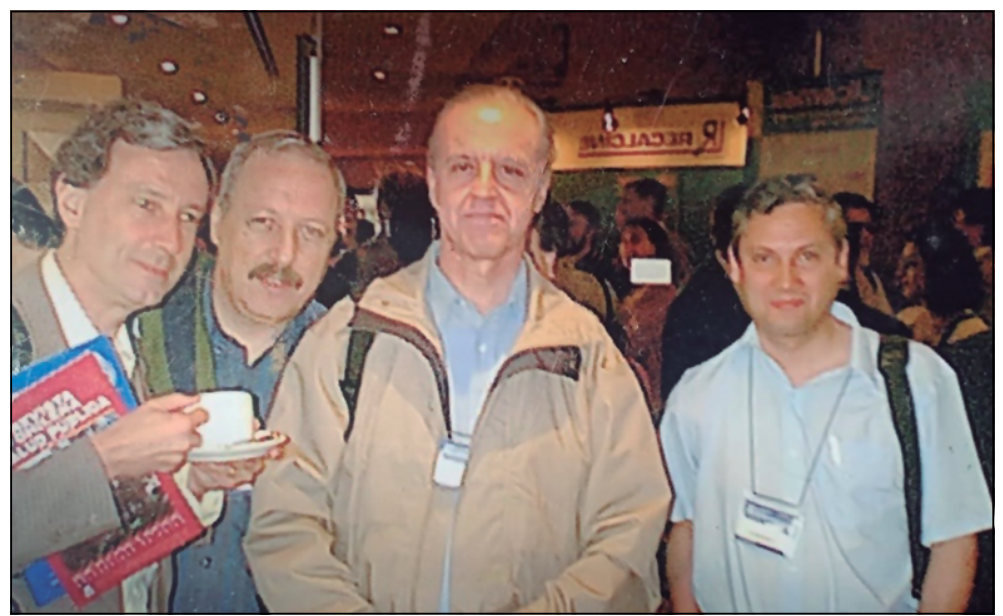

Congreso Chileno de Gastroenterología 1999 (Viña del Mar), de izquierda a derecha: Dr. José Brkljaca, Dr. Felipe Finkelstein, Dr. Fernando Gutiérrez, Dr. José René Sánchez.

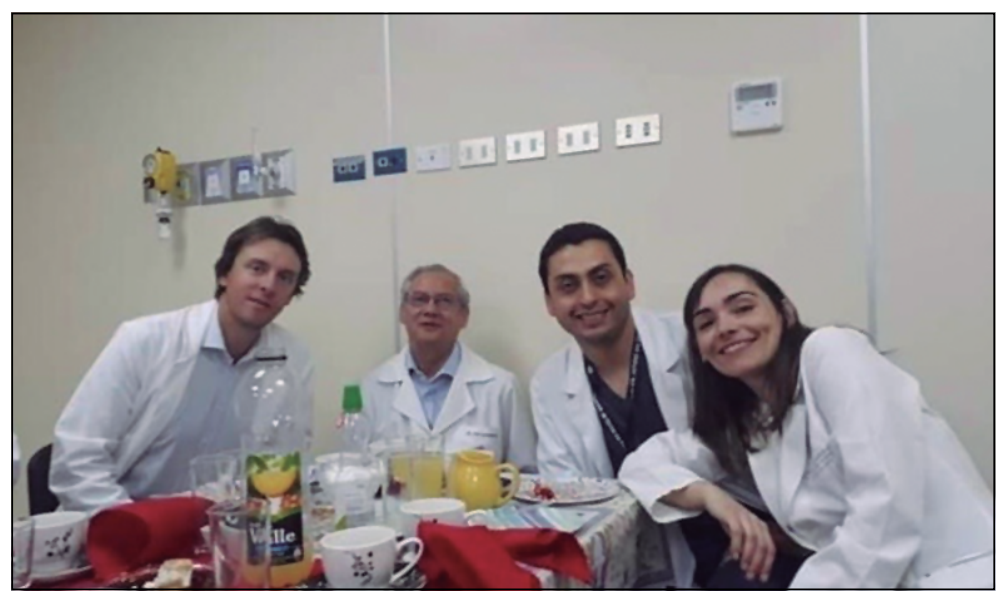

Celebrando el día del médico, diciembre de 2019, de izquierda a derecha: Dr. Gustavo Walsen, Dr José René Sánchez, Dr. Alex Arenas, Dra. Blanca Norero.
Partícipamos año a año de los congresos de Gastroenterología".

Si bien René no era una persona locuaz, él predicaba con el ejemplo, sin duda una de sus características más reconocidas era su inagotable capacidad de trabajo y su enorme entrega por los pacientes, sus cercanos lo describían como incansable, al punto que uno de sus queridos colegas del Sótero, el Dr. Fernando Gutiérrez, en algún momento lo apodó el "Duracell, imposible de seguir", ni siquiera por sus compañeros más jóvenes, que en los años más recientes tuvieron el honor de trabajar a su lado. René contagiaba con su espíritu y sin duda era él quien marcaba el ritmo de trabajo del grupo y quien forjó la mística aguerrida y de entrega que, actualmente, caracterizan a la Unidad de Gastroenterología de su querido Sótero.

Siempre se preocupó de que todos los problemas del día quedaran solucionados, ¡nada de dejar cosas para mañana! Era habitual escucharle decir "voy a darme una vueltita a la urgencia por si quedó algo pendiente", y casi siempre volvía al Centro de Endoscopia con algún paciente, muchas veces "camillando" de ser necesario, para realizar algún procedimiento endoscópico de última hora. El equipo de endoscopia sabía, que cuando él estaba de turno, no se desarmaba el pabellón hasta que el doctor no se despidiera, diciendo adiós a cada uno del equipo que había trabajado con él ese día.

$\mathrm{Su}$ calidad humana la demostraba en cada detalle. Por ejemplo, para las navidades, René se preocupaba de regalarle "un chocolatito" a cada persona que había trabajado con él durante el año; guardando la particularidad de que cada presente iba con el nombre del destinatario escrito por él.

Siempre estuvo al lado de su personal, si alguien del equipo enfermaba, le confiaban su salud al Dr. Sánchez, quien lo acogía y atendía solucionando la dolencia. Nunca dejó de participar con ellos hasta en las actividades más sencillas, compartiendo un tecito con un pedacito de pan. Esto le valió el reconocimiento expreso de sus equipos de trabajo.

$\mathrm{Su}$ amor por la profesión, su consecuencia y su entrega incondicional por los pacientes, fue lo que lo llevó a seguir trabajando durante la pandemia, desoyendo los consejos de sus colegas e incluso de su propia familia, que lo instaban a quedarse en casa por pertenecer a la población de riesgo, pero René no dejó de atender pacientes. Según él mismo refirió, era en estas circunstancias cuando más lo necesitaban; decía que si no los atendía después iba a ser peor, ya que llegarían todos descompensados a un servicio de urgencia colapsado.

Querido René, es para nosotros muy doloroso 
tener que despedirte, jamás pensamos que sería ahora, ni mucho menos de esta forma. Fuimos muy afortunados de haber sido tus compañeros, fuiste un ser humano excepcional, apreciado y respetado por todos nosotros, una persona respetuosa, amable, honesta, humilde y sencilla, con un corazón de oro que no cabía en tu pecho, con una capacidad de trabajo y sentido de responsabilidad encomiable y de una entrega admirable por tus pacientes, que de seguro te extrañarán, y por quienes diste todo, hasta el último momento.

No imaginas lo mucho que te vamos a extrañar, pero quédate tranquilo y no te preocupes, que todo lo que aprendimos a tu lado, tu espíritu de trabajo y tu entrega, quedará grabado para siempre en nuestros corazones, en beneficio de tus y nuestros pacientes.

Dr. José René Sánchez Bascuñán, no olvidaremos tu sacrificio ejemplar. Colega y amigo descansa en paz.

\section{Referencias}

1.- El Arte de Amar. Erich Fromm. Ediciones Paidós Ibérica. Ciudad de México, México. Fecha de publicación 1959, 2000.

2.- https://www.diariofutrono.cl/noticia/actualidad/2020/05/ proponen-que-proximo-hospital-laguino-sea-nombradodr-rene-sanchez-bascunan

3.- http://www.hospitalsoterodelrio.cl/

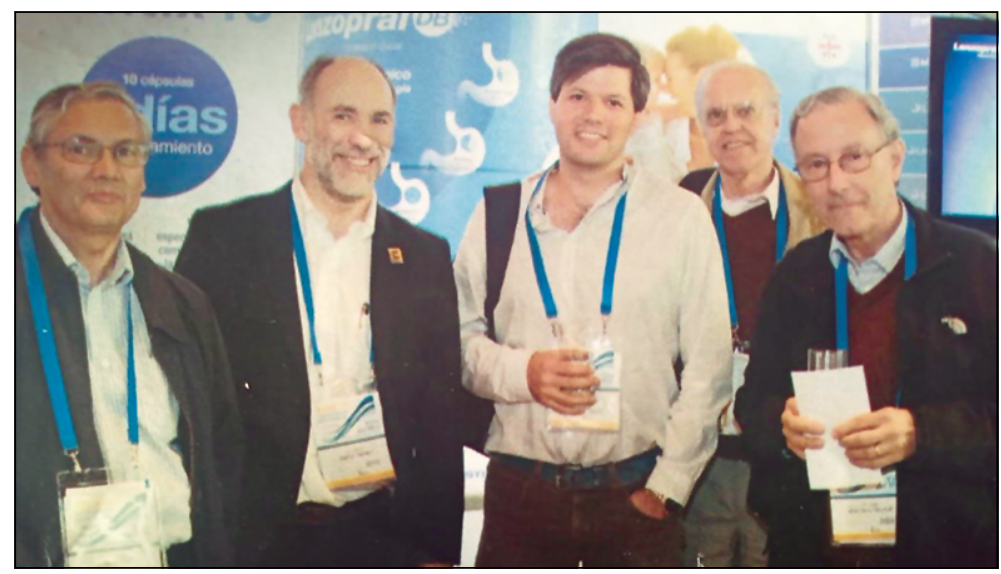

Congreso Chileno de Gastroenterología 2015 (Viña del Mar), de izquierda a derecha: Dr. José René Sánchez, Dr. Marco Arrese, Dr. Juan Pablo Ortega, Dr. Fernando Gutiérrez, Dr. José Brkljaca.

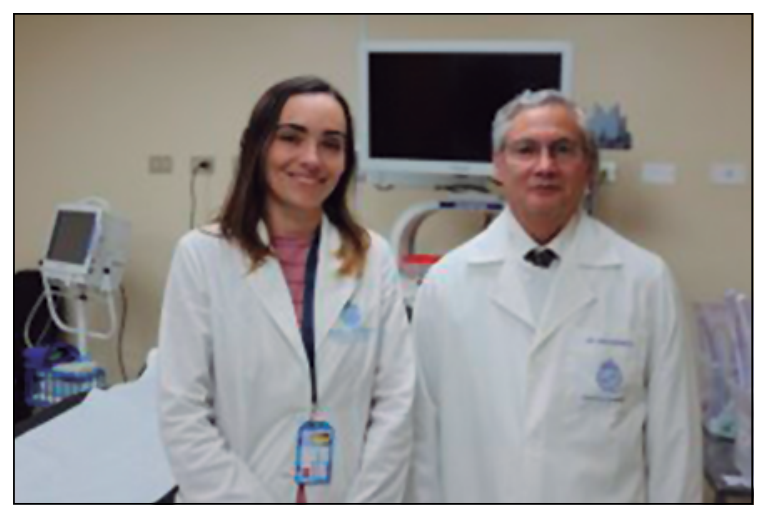

Día Mundial de la Hepatitis en Hospital Sótero del Río, julio de 2018. Dra. Norero y Dr. Sánchez ${ }^{3}$. 